\section{B A Institute of \\ YK Business Administration \\ 六下 \\ Karachi \\ Leadership and Ideas for Tomorrow}

Business Review

Volume 10 Issue 2 July-December 2015

7-1-2015

\title{
Strategic dimensions of organizational productivity (A case study on the proposed HRD directions for modern companies)
}

Nadir Ali

Skyline, University, UAE

Follow this and additional works at: https://ir.iba.edu.pk/businessreview

Part of the Human Resources Management Commons, Organizational Behavior and Theory Commons, and the Strategic Management Policy Commons

\section{(c) (1)}

This work is licensed under a Creative Commons Attribution 4.0 International License.

\section{Recommended Citation}

Ali, N. (2015). Strategic dimensions of organizational productivity (A case study on the proposed HRD directions for modern companies). Business Review, 10(2), 116-129. Retrieved from https://doi.org/ $10.54784 / 1990-6587.1357$

This article is brought to you by iRepository for open access under the Creative Commons Attribution 4.0 License and is available at https://ir.iba.edu.pk/businessreview/vol10/iss2/8. For more information, please contact irepository@iba.edu.pk. 


\title{
CASE STUDY
}

\section{STRATEGIC DIMENSIONS OF ORGANIZATIONAL PRODUCTIVITY (A CASE STUDY ON THE PROPOSED HRD DIRECTIONS FOR MODERN COMPANIES)}

\author{
Nadir Ali, Skyline University, UAE
}

\begin{abstract}
Strategic directions are the processes that lead organizations towards the achievement of the promises mentioned in mission \& vision of modern companies. Most strategic minds come from the practices and experiences of corporate dimensions. Dimensions can be learned but cannot result unless experienced in the corporate world. Understanding strategic dimensions of modern age can lead modern companies. This case study will cover all important parameters of organizational productivity with special reference to the proposed strategic HRD directions that are considered as the gist of this case study. The first dimension is HRD Tier that is connecting with leadership in the organization, second is HRD transformation that is the manual workflow towards the technical flow for employees, and third one is an e-HRD phenomenon for collaboration \& connectivity in the modern organizations. This case study is an attempt to propose Strategic Tiers (TM-Technology Management, HR-Human Resources \& CL-Corporate Leadership), HRD Transformation (HR Processes \& Developing employees) and HRD Collaboration (Electronic Phenomena). This case study will report on all important parameters that will enhance the productivity in modern companies. The purpose of the case study is to identify strategic directions through HRD initiatives as Tiers, Transformations \& Collaborations in MNCs. The purpose of this case study is to explain the proposed directions to help in achieving organizational productivity. Thisis mainly designed to identify Strategic directions to link HRD Tiers, HRD Transformations\&HRD Collaboration formodern companies.
\end{abstract}

JEL Classification Code: O15, O32, O47.

Key words: Strategic directions, HRDdimensions and Organizational productivity.

\section{Introduction}

IT world \& HRD strategies are changing rapidly. What has taken us here is not going to take us there? We need to explore new ways that have not been imagined before. This is the survival philosophy in today's high tech networked world with seamless socially connected society. Exploring ways don't mean to mention buzzwords of advanced education, electronic training or HRD with intellectual capital but very proven ways of achieving them. One of the proven ways is strategic HRD directions towards organizational productivity based on its collaborative role in the organization. Modern organizations set the goals to connect the departments at a real time aspect that maintains the pace with the changing phases of technological updates, employee motivation, customer needs, governments coordination, internal communication \& external connections. This study proposes three HRD directions to achieve organizational productivity\& presents the situation to help modern companies to set goals on regular basis. The proposed directions will ensure that the purpose is achieved with well structured \&aligned pattern in the company. First is the Strategic HRD Tiers that are 
proposed to justify the link between Technologies, Human Resources \& Corporate Leadership. Such strategic tiers are the basis for setting organizational structure in order to effectively reaching the set targets. All tiers are playing their role in managing the directions but the middle tier as HRD will play a central role to connect the TM \& CL as shown in the table of strategic HRD tiers. The second is strategic HRD Social Transformation that can set the directions to transform the traditional systems towards effective one to achieve the efficiency in the organization. This also ensures the social mobility, social patterns \& coordination among employees. The third is Strategic HRD Collaboration. This direction is the technological response through the help of HR modules to maintain organizational programs. This direction is set through $3 \mathrm{Es}$ that are proposed is order to have required help for technology to compete with competitors. In the latter part of the case, all the proposed HRD directions are comparatively analyzed for the purpose of evaluating the critical directions that require more attention by the modern corporate leaders. Modern organizations work \& rotate around three tiers namely TM tier that relates to technology management \& covers facilitative platform for collaborative organizational processes. The second is HR Tier that is about human resources that manages people \& people with technology in order to create a wide range link among departments. The last one is pertinent to Higher hierarchy that is known as Corporate Leadership Tier that covers structured decision making roles. Above proposed tiers ensure a smooth working trend in modern organizations. This is considered a guideline for Modern Corporation to be effective in installing technology, managing people and leading from the front to hold organization with strength from TM \& HR tiers. The successful companies like IBM (USA), Emirates Airline (UAE), TATA (INDIA), Microsoft (USA) and other successful companies have generally achieved success through utilization of the sequential patterns mentioned in this paper. IBM showed accurate strength in high TM tier with best customized machines \& services. This can come from the structured decision approach of the company. The leadership was competent enough to formulate required strategies to achieve the mark. They did it through holding CL \&TM tiers and introduced HRLP (Human Resource Leadership Program) to create a greater corporate link using HR tier around the organization. This brought success in many years and still sticks to achieve at higher levels. HRD is the part of HRM that covers managing \& developing people. Today is an age of technological processes that facilitate all technological, theoretical, scientific \& Psychological aspects through information technology processes. Such processes are the guaranteed flows of saving time, special links and faster communication in just few clicks away. Such processes promoted the HRD activities and supported HRD aspects into most effective ways as work flow automation. It was much difficult to give employees everything through traditional ways in few decades back but today the faster e-HRD flows are much better and facilitate all employees with best response. The best strategic step in smooth conduct of organizational activities is the quick response activity of HR Development in HR department. Social transformation trends have changed the role of HR over the years. The tornadoes of technology updates wrapped all old stuff trends and made people compelled to build new society at the similar faster pace as it moves these days. Whenever, such transitions occur the role of HR becomes crucial as it is attached mostly with dealing people. Companies are facing an increasing demand concerning the modern business and organizational performance. The technological innovations push the companies to move towards understanding full potentiality of today's information superhighway to create e-platform for HRD. But e-HRD is a term proposed in this case as the process of managing workforce through electronic \& internal connections. Electronic connections are the HR systems connected to other departments while internal connections are the facilitative platform for employment portals to get company information and access company handbook.

\section{Supportive Literature Review}

$\mathrm{HRD}$ is also considered as leading people towards required development for the company. However, in order for HRD to make a contribution it needs to move away from a 
process-oriented and administrative approach to one that is more strategic, and in doing so take a leadership role in the development of people (Gold et al,2011). Strategic HRD is mainly supportive to organizational development. It helps organizations to develop employees that result in organizational development. Strategic HRD approaches as T\&D (Training \& Development), OD (Organizational Development) and other required models contribute towards company progress. As well argued by Grieves \& Garavan (2003: 108) suggested that: 'it emerged as a resultof a new climate of disorganized capitalism and from debates within organizationaldevelopment.' Garavan (2007: 25) defined SHRD as a 'coherent, vertically aligned andhorizontally integrated set of learning and development activities which contributeto the achievement of strategic goals'. Corporate leaders also focus on HR development to come up with best HRD strategies to become better competitor in this competitive world. Human resources provide the potential for sustained competitive advantage through the use of SHRD to develop competencies that are firm-specific and generate tacit organizational knowledge (Lado and Wilson, 1994). There are various strategies to achieve various goals. Organizations are in search to find the varied level of strategies to adopt and lead to productivity. As well said by Snell-1992 that different organizational goals and objectives require different types of behaviors and therefore different SHRD practices (Snell, 1992). The study of Human Resource Development has increased the demand and understanding of collaborative \& coordination among departments and people working in different departments. The learning \& development function of HRD has advanced over time and is now considered a strategic element in supporting collaborative relationships with key stakeholders such as senior management, HRM, line managers and employees (Ulrich and Beatty, 2001). All organizations have clear objectives on profitability, image and productivity. This makes HR managers to innovate strategies \& functions that may be better and may not be copied by the competitors. The key objective of any organization is to remain profitable, ensure long-term viability by engaging in processes/systems/procedures that ensure a competitive advantage, achievable through utilizing the unique resources that cannot be easily copied (Ulrich, 1997). This case study has evaluated the role of HRD and linked its performance with organizational productivity. Most of the HR functions are linked to technology, talented people, demanded workforce and sound HRD collaboration within the company. HRD is main element to innovate, adopt and require the relevant resources, capability and competitive advantage to represent company in better way. Through an extensive review of the literature, a consensus has been reached as to the suggested relationships between resources, capabilities and competitive advantage (Makadok 2001, Eisenhardt and Martin 2000, Zollo and Winter 2002, Teece et al. 1997, Winter 2003, Festing and Eidems 2011). There are many changes happening but social transformation in this century has rapid pace based on the post industrialism. HRD is taking advantage of information technology to deal with social transformation of employees. As Dutton 1999 considered such process as shaping tele-access or reconfiguring access. (Dutton et al, 2003). Social Mobility, Technological Transformation Trends and HRD have much impact of rapid social transformation. Most of the changes have come from the countries having dominant role in business, education \& technology.Strategic HRD directions emerged as most demanded elements to achieve productivity.

\section{Strategic HRD directions for productivity}

\section{Strategic Tiers}

The strategic HRD domain was always available but didn't work because it was not supported better by slow technological system in decades back. This age has brought facilities as connected the TM tier with CL tier and getting required help of coordination from HR tier. Competitive organizations do not only need to have hundred strategies based on marketing, service, HR, technology, databases, competencies, changing modes but just to focus on two 
departments as HR \& IT. The connection of these two departments will cover all successful aspects of the company and can gear up to be in better position.

\begin{tabular}{|lllll|}
\hline \multicolumn{1}{|c}{ Strategic Tiers } & \multicolumn{1}{c}{ Management } & Decisions \\
\hline TM Tier & $\bullet$ & IT systems & $\bullet$ & Creating platform \\
(Technology & $\bullet$ & Collaborative networks & $\bullet$ & Connecting to all \\
Management) & $\bullet$ & Technology Updates & $\bullet$ & Managing with all \\
\hline HR Tier & $\bullet$ & People & $\bullet$ & Induction \\
(Human & $\bullet$ & Training & $\bullet$ & Development \\
Resource $)$ & $\bullet$ & Technology & $\bullet$ & Utilization \\
\hline CL Tier & $\bullet$ & Moving to directions & $\bullet$ & Leadership \\
(Corporate & $\bullet$ & Identifying systems & $\bullet$ & Innovation \\
Leadership) & $\bullet$ & Adopting all systems & $\bullet$ & Decisions \\
\hline
\end{tabular}

Table \# 1 (Strategic Tiers)

Some companies have already utilized such steps but failed due to lack of experience and vision in understanding the importance of the two departments with special reference to the strategic HRD domains. Some leaders have to face the wall because they planned various strategies as to internationalize the products, having talented people, training them in developed countries and installing all technological aspects, this remained unsuccessful because they were just done without proper planning as it covered in strategic HRD (TM, HR \& CL tiers). Some successful companies utilized HRD strategies in different ways. Emirates Airline invested in HR tier who brought technical minds to identify the required domain HR tier that was much supported by the CL tier who were geared to present Emirates in every corner of the world. The best structured decisions from CL tier happened when they started to identify best HRD people who later brought working, technical \& managerial approached people from all over the world. They maintained huge diversity and managed to be amongst the top airlines with best of the breed systems and customized services to be a brand mantra among workers in the world. The tiers are still being revised and leading towards success. TATA \& Microsoft invested huge money on technology and then achieved HR tier as required. The Japanese companies are much focused on technological tiers while EU \& Gulf countries are first investing in HR tier who are then identifying some technical tier to be installed in the company. This may not be the case all the time but most of the time it has happened in some modern companies. The identification and inclusion of such explanation in this paper is to explain the strategic HRD importance with reference to all tiers. The middle tier HR is the collaborative among other two tiers and justify to be an strategic domain. This is the reason, it exists in the middle and makes sure both other tiers are properly intact with rest of the organization. Above domains of different tiers can be beneficial if adopted in the way as it required otherwise this will result in no success. Adoption in this way is to understand the gist of domains. The biggest opportunity for any organization is that this model is available in sequential steps. This needs to be understood, evaluate current position of the company, see the potentiality of strategic HR development through HR department and check the aspiring leadership of the company. If anything has any lack, then this may not work. The best way is to copy as IBM did is the communication and putting right steps of TM, HR \& CL. Proceedings towards its success as opportunity, we need to check the volume of the company, business of the company, dealings of the company and then check the technological position of the company. Later check the strategic partners, who are HR managers, evaluate the processes, coordinate with HR, other departments and contribution over the years. This moves towards higher cadre of the company as CL is the structured 
decisions making authority. After connecting all of them, evaluate the connections of HR tier with rest of the other tiers. Some challenges like IT where systems can be expensive \&company may take time to adopt, staff is required to be available to handle the technical affairs and due coordination all the time. HR related challenges could be the staff with no good backgroundand busy in just evaluating employees' performance only. HR managers should put best people in different projects and CL tier can be a greater cooperation from employees. TM is the required aspect; it requires talented \& technical people to support company not on the basis as telling people that viruses can be controlled this way but a real solution that adds value to employees' working environment. All mentioned tiers are interdisciplinary and require a leadership sense to adopt and instill in top tier first and then spread to other tiers. This strategic HRD domain can be much confused if top tier expect a lot from the employees whom they know cannot deliver. Evaluate the expectation with reality and available potentiality to lead the company in effective manner. Depending on the technology is fair but dependency on people who you know they deliver is good but if they can't, then it is disaster. Train the top tier before you train TM or HR tier. Understand HRD before you install HR system.

\section{Strategic Social transformations}

This relates to Social transformation trends and their impact on HRD in modern times. Social Transformation is a process in which we transform our present status into the achieved one through our choice and interest. Sometime, it occurs easily and sometime it becomes complicated as individuals adopt it by choice or by no choice. By choice means people want it, by no choice means, it is unavoidable as the world moves and individuals move accordingly. Social transformations are not considered the transformations based on any one identified element but can be varied of its nature. It is more towards trends of changes mostly pressured by technology, preferences, ambitions and education. History can witness that human being and society kept changing with the changes in choices that affected economy, community, work styles, dealing styles, travelling, competition, politics, power, leadership and other things in the society. The Social Transformation has a great impact on HRD activities. HRD always evaluated to look after employees, orient them, answer them, help them, train them, help them clarifying issues, counsel them and motivate them to become a good change in the organization. This trend is the sign of making an organization as social organization that benefit employees at all levels. Through this, organizations use social media in all management activities as recruitment, selection, coaching, training and much more. Social media is such a powerful tool that impacts most of the HRD activities and later transforms all working styles into new styles. This is the reason where Social Transformation at today's faster pace has become a greater push on HRD to change traditional dealing styles into socially networked styles.It has given a new life to managerial communication. Everything that happens is always organizational conversation but anything that happens now is organizational social communication. Social media is a facilitative platform for HR department that helps to broadcast all HR activities \& capabilities to whole organization within (Employees) and outside (Competitors). HRD has always been in a search of ideal game plan to face the trends of social transformation specially due to the powerful changes of social media. Such smooth working can enhance the productivity. All this emerged at rapid pace as social mobility \& social functionalities through facebook, twitter, linkedin and many others. Above 90 percent people want to get technical or required education to achieve something as they could progress towards upward mobility. This has significant impact on the modern organizations where technical people negotiate mostly on the financial rewards as they normally change the jobs based on the better offers in order to achieve upward mobility. This trend has shown much impact of HRD activities. Such mobility made HR to change social trends as demanded by the society. The change in education will make change in status that ultimately will have high impact on social stratification based on the preferences and styles. There are various factors that have become the causes of Social Transformation from 
time to time but following few factors are main causes these days. The following model is the main foundation of coping up with changing trends of transformations.

\begin{tabular}{|c|c|}
\hline Social Mobility \& Transformation & Strategic HRD practices \\
\hline 1. Skills (Hard \& Soft Skills) & \multirow[b]{2}{*}{ TRAINING } \\
\hline 2. Diversity (Labor \& Talented) & \\
\hline 3. Lifestyles Old \& New Styles & \multirow[b]{2}{*}{ CONTROL } \\
\hline 4. Changes Local \& Global Level & \\
\hline 5. Infrastructure Transportation \& Delivery & \multirow{3}{*}{$\begin{array}{c}\text { ORGANZOATIONAL } \\
\text { DEVELOPMENT }\end{array}$} \\
\hline 6. Technology Soft \& Hard Technology & \\
\hline 7. Education Social \& Engineering Sciences & \\
\hline
\end{tabular}

Table \# 2 (Strategic Social Transformation)

Organizations always respond through HRD towards social understanding\& transformation. This model lists seven points of social transformation that people exponentially grow. Skills are the expertise that help people to perform better but company puts those people in diversity to learn more. This transforms to the changing life style of people. It depends in the caring family, experiences, career growth and increase in choices. It happens \& affects everyone around companies and this makes companies bring some changes of dealing \& helping employee in change management activities. HRD directions are always clear to deal above all points. Company also expand and transform changes. Technology is the biggest factor to social changes. Education is a great tool of social transformation. Once you start getting education you start changing your thoughts. Education always changes the nature of living, working and preferences as Diane (2005) suggest moving from dominator model to partnership model of education. These models describe systems of belief and social structures that either nurture of support (Diane Eisler, 2005). Above foundations have changed the methods of work \& processes in the Organizations. Social mobility has totally transformed basic characters of an organization specially the structure and the strategies the way people want to carry out in today's age. This has impacted much with the social functionality as HR uses facebook, twitter, linkedin for different processes as communication, dealing, recruiting, selection \& rewarding. Social transformation has huge impact on HRD to revise, renovate, restructure and modify the changes concerned to employees. Everyone has good plan in the career, next cadre or any social needs. In this regard, HRD has to explore the modern techniques to handle the choice of social transformation connected to employees for the long term stay and attachment with the company. All the good companies and their HR departments will use HRD (Human Resource Development) in-line with the above model mentioned in this study. If above framework is followed properly then things may move to progress and cope up the changes happened due to social transformation trends.

\section{Strategic Collaboration \& Connectivity}

The miraculous development in the emerging HR module has brought very relaxed activity which inspires business and HR professionals to carry out business activity not only within the boundaries but outside the borders as well. The advancement in networking gadgets is continuously increasing to bring smooth working environment for HR to maintain speed, coordination, collaboration and flexibility in various phases. Every traditional term has flourished towards progress with the faster pace of technological aspect like Marketing (etailing, e-marketing), Advertisement (internet commerce), Business links (electronic data interchange), effective Electronic Data Privacy Department (ERPs and Electronic 
procurement), Electronic Business (internet business, electronic commerce), Relationship marketing (CRM, e-banking), Traditional trading (e-trading), Mobile Business (mobile commerce), Supply Chain Management (technology enabled SCM) and most important eHRD (e-training, e-recruitment and e-meetings\& e-workflow). All of this is based on the advancement in the networked environment. Strategic collaboration among departments is an initiative of HR departments that makes good connection for employees through HRD (Human Resource Development) process. The processes are facilitated by e-HRD activities mentioned as e-phenomena

\begin{tabular}{|llllll|}
\hline Companies & HRM & E-Phenomena & HRD & Success \\
\hline Business & Internal \& External & 1. & E-Bus & Internal \& & Productiv \\
Profit & environment & 2. & E-Com & External & ity \\
Image & & 3. & E-Logistics & & \\
\hline
\end{tabular}

Table \# 3(Strategic e-Phenomena)

The model has a technical role in organizational productivity. It is a foundation platform for HR professionals that leads company to rely on some important technology aspects. HRD role in this mode is to connect the missions with the available opportunity through strategic directions from company's business towards strategic partners as HRD professionals. They create huge pool of supportive technologies that connect the company with customers, suppliers, governments and other important stakeholders. This leads in a very smooth way to reach to productivity. This model is basic theme of what companies can plan, focus, prognosticate, enter into the competition, adopt technology and change with the faster pace of not only technology but customer's performance and competitor's strategies. This model is the guideline for the companies to evaluate them and change according to the required demand of the world's competitive rule. HR sets company directions on the system flow of $3 \mathrm{Es}$ in modern era. The model mainly comprises on five factors which are named as five pillars in this case. the first two are the company's concern, plan and programs while the last two are the same but have been included for the purpose of checking of what has been planned is the same or going to success or failure on other basis. This check will help in making some modifications if required; it is just preset, precautionary step to work on. The middle pillar which is the most important is regarding the marketing analysis to check what is being done or what is the trend? The sequential flow of 3Es related to HRM is to evaluate companies on the basis of business trends, profits earned and build an image. This is covered through HRM that contains on the proper recruitment \& selection of right candidates through an evaluation on the basis of internal \& external environment related to workforce trends, employee diversity and employment demands. HRM can be utilized through IT enabled networks to maintain the requirement of attracting customers. The HR role in 3Es is based on the business visions. HR helps companies to be in the connection to adopt $3 \mathrm{Es}$. HR coordinates with IT department to plan \& focus on E-business activities to reach customers in a better way than competitors. HR uses e-commerce means to be connected with the government to some legal \& business orientations. HR shows the role of identifying good people to get the company products into the hands of customers through logistics as elogistics trends. The next HRD is term coined for HR and ensures that good employees are trained, coached and properly mentored to achieve the last block as success. First pillar that is consisting on business, profit and image is the company's plan \& goal. Organizations want to enter into business as they could share what competitiveness they possess. The last factor of the pillar is image, which is built on company's qualititative profile, service, support or flexible activities, which they can offer to the customers. Now when business and image is adequate enough, they are no doubt eligible for reaping the profit out of any competition. This takes time but once built, can take the organization to the climax. HR motivates how to get success in first pillar that is based on the source given in the pillar number 2 . The second 
pillar's internal factors are important company concerns based on the HR planning as intellectual capitals, skilled IT heads, well-established information systems, unique methods, advanced network set ups, on the other hand the external concerns are other's strategies. HR evaluates outside environment to learn the competency and incorporate into their company. HR moves to find the answers with coordination into other departments. Third pillar focuses on the consortium of 3Es. It is not easy to know what competitors are doing but HR research towards technology can help us what customers are doing? If company comes to know about customers, you will definitely have some idea of competitive strategy because ultimately they also do the same as they try to satisfy customers, technical change is the factor which pushes the organizations to bring a change or innovate in their setup, the most important is the technological flow in electronic business, a business which helps the customers to know what we offer them, the ways to reach them and HR efforts to adopt the way to make customers to stay with them. If any company is not connected with the world then it has no place in the world's competitive team. This connectivity gives organizations flavor of installing good ERP system, customized SCM software, HRIS and detailed databases to manage the information overload. The connectivity gives a way to track your customers around the world. This pillar is analyzed on the basis on these main factors: one is market analysis where companies research the potentiality of business, where is the business existing, what is the competition which pulls you to serve in the same way as competitors are doing otherwise you will be alone. The third one, very important is regarding the strategy which is based on the first two analyses and competition; the strategy will be to focus on E-Bus and other online activities. The fourth pillar is there just to check whether the internal or external concerns are same or have changed to some extent and fifth is also a help that checks whether we have achieved the expected targets or not. HRD plays a role of developing employees in all means as required.

\section{Comparative Analysis, Discussion \& Application}

This is not easy to compare and decide which one is more important rather to report each one in its effective role and its pertinence to another direction. Strategic directions of the companies keep changing with the changes in competitors' strategies, customers' choices, employees' motivation, government's requirements and relevant research patterns. HRD directions are always open and evaluate such directions in order to instill as early as possible to make to the list of real competitors. The proposed models as strategic HRD directions are the real solutions for modern companies to get more than their share. Proposed directions are the modern techniques to achieve productivity in no time. Time is crucial in today's age as it changes the preference of customers. This makes organizations to change their strategies to maintain the same cadence of organizational productivity. The proposed HRD directions will give a constant successful tactic for modern companies. This is crucial if achieved, adopted and aligned in most effective manner.

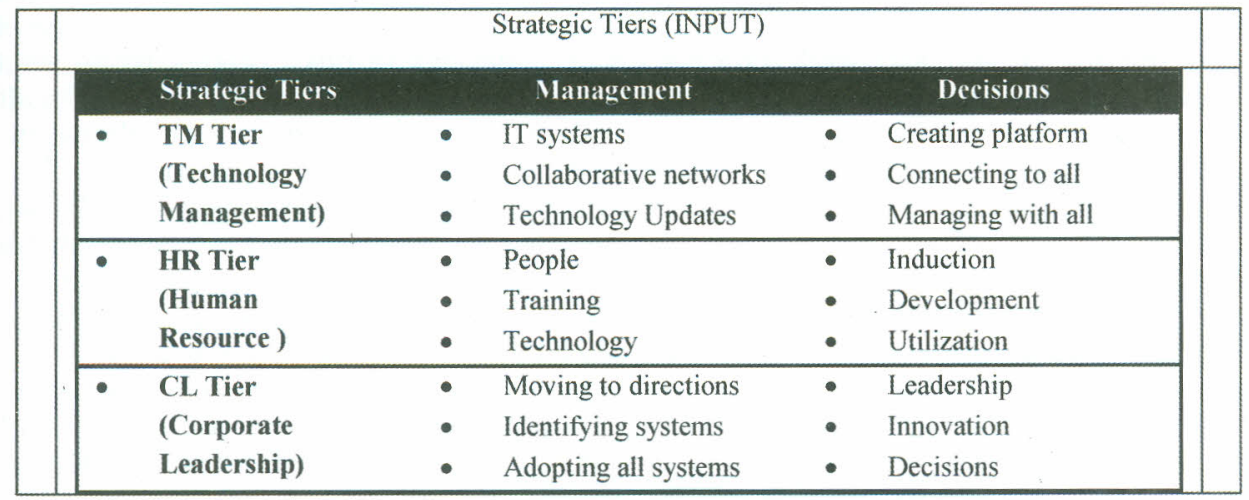


Strategic Social Transformation (PROCESS)

\begin{tabular}{|c|c|}
\hline Social Mobility \& Transformation & Strategic IIRD practices \\
\hline - $\quad$ Skills (Hard \& Soft Skills) & \multirow[b]{2}{*}{ TRAINING } \\
\hline - Diversity (Labor \& Talented) & \\
\hline - $\quad$ Lifestyles (Old \& New Styles) & \multirow[b]{2}{*}{ CONTROL } \\
\hline Changes (Local \& Global Level) & \\
\hline $\begin{array}{l}\text { Infrastructure (Transportation \& } \\
\text { Delivery) }\end{array}$ & \multirow{3}{*}{$\begin{array}{l}\text { ORGANZOATIONAL } \\
\text { DEVELOPMENT }\end{array}$} \\
\hline - Technology (Soft \& Hard Technology) & \\
\hline $\begin{array}{llll}\text { Education } & \text { (Social } \\
\text { Sciences) }\end{array}$ & \\
\hline
\end{tabular}

Strategic E-Phenomena (OUTPUT)

\begin{tabular}{|c|c|c|c|c|}
\hline Companies & HRM & $\begin{array}{l}\text { E- } \\
\text { Phenomena }\end{array}$ & IIRD & Success \\
\hline $\begin{array}{ll}\text { - } & \text { Business } \\
\text { - } & \text { Profit } \\
\text { - Image }\end{array}$ & $\begin{array}{l}\text { Internal } \\
\text { External } \\
\text { environment }\end{array}$ & $\begin{array}{l}\text { E-Bus } \\
\text { E-Com } \\
\text { E-Logistics }\end{array}$ & $\begin{array}{l}\text { Internal } \\
\text { External } \\
\text { environment }\end{array}$ & Productivity \\
\hline
\end{tabular}

Table \# 4 Combined Strategic directions (Comparative analysis)

The best effective manner is to evaluate \& understand all proposed directions and link each other to be flexible around whole organization. This makes organizational leaders to achieve organizational productivity as planned in strategic missions \& visions of the company. Modern organizations may have some other strategic dimensions but don't have choice which one is most suitable for long term achievements. This case study proposed suchconstant \& developed strategic directions that are sequentially organized to give long term benefits to the organization. Though, long term productivity may not continue as focused by corporate leaders but some good strategic direction can ensure desired organizational productivity at rapid pace. Such directions are proposed in this case study and suggested that companies need to have a sense of adopting modern directions as required. The strategic HRD directions in form of models are strategic HRD tiers, Strategic HRD transformations \& Strategic HRD collaborations. The first one is based on the input in the company through inducting people, developing people and motivating people to stay in the company. The second one is considered as the process in the company that transforms the people, mission, vision and work process into the desired results. This is based on the dimensions that are important to handle through social mobility, transformation and education of employees. The third oneis related towards an output in form of collaboration \& connectivity among the elements of an organization at various levels \& departments. This is based on the modern usage of technology in business, communication, collaboration, connections to all stakeholders as customers, suppliers, government and employees through proven technical means in the company. In all above flows from input, process, output and strategic combinations, the HRD exists at all steps that ensure the connections among all strategic directions to achieve organizational productivity. This was always a mix trend of strategic directions throughout decades. Few decades back, it was based on technology only but did not work. The successful company trends are not based on any such direction but different dimensions that are connected with each other. Good companies help employees in providing \& guiding with different dimensions of strategic directions with special reference to the role of HR development at HR department. The planned organizational strategies can only 
be decided when they are not sequentially aligned towards the required strategies, available potentiality of employees, supportive technical system, readiness to social transformation and greater collaboration among the departments. Though, some strategies can be planned at individual level but can never be aligned separately for longer time. It has to be in line with other departmental strategic domains to ensure the collaborative working environment. This is the reason; this case has proposed three different directions with possibility of being connected to each other. The purpose of this paper is to get desired organizational productivity that can only be ensured through sequential flow of HRD tiers, HRD transformation and HRD collaboration. The proposed directions are not designed for any one department or level rather innovated as the central policy dimension of the organization in order to achieve desired productivity. Productivity in this case refers to the image, success, profitability and long term impression on the customers and a term of success for employees as well. All these strategic directions are the central domain for modern companies based on international or multination levels. MNCs can take much advantage of the directions as using HRD tiers as input when they plan the need for employees, develop and align them in the most suited departments. They can transform their ambitious driven behavior into high class tactic through training at home \& outside. In the last, they can put employees everywhere at head office or decentralizedcenter at any other country or just get benefits of employees' expertise through collaborative \& connectivity in the world. The best way to innovate the proposed strategic direction is to combine HR managers, IT managers \& CEO for working on HRD strategic tier. This way, the people will contribute the expertise intheir own domain. The second phase should comprise on the same as HR manager, IT manager \& CEO and also add Marketing manager to have some more opinions on the social \& marketing transformation in the company. The third phase will also remain same as HR manager, IT manager, $\mathrm{CEO}$, Marketing manager and one more added as Finance Manager who will notice the criteria of financial viability \& concerns throughout productivity processes. The strategic leaders will always be there in the whole process of strategic direction from input (HRD tiers), Process (HRD transformation), and output (HRD collaboration). Few companies can be at some losses if above plan of strategic leaders is missing in any form. Strategic HRD directions can only be successful implementation if proposed directions are instilled by the proposed strategic team based on the strategic managers from initial to last levels.

\section{Case study findings}

This case study was initiated to achieve the purpose of identifying the strategic HRD directions for modern companies. The study found that organizations have various strategic levels to identify strategies but HR usually takes a lead in the innovation, much cooperation towards higher levels and contribute in the higher strategies as well. This study found that organizations may get across three crucial strategies in the modern era. This case study research has found and proposed such three strategies named as Strategic HRD directions in this paper. The strategic HRD directions are placed in most sequential manner to help companies to achieve their desired result. The case study found that the proposed strategies will have a high impact in the progress of the company and can help managers to achieve the productivity in an effective manner. The case found that proposed strategic HRD directions are the systematic flow of organizational working process that is supported by the structure, purpose, technological workflow and employees. This is put in the form of input as first direction, process as the second direction and output as the final direction. These directions are mentioned separately throughout the paper including one combined comparative analysis of strategic HRD directions. This has found that companies are in greater need to adopt \& apply the proposed strategic HRD directions that specially designed for achieving organizational productivity. The case found that there is a corporate requirement to adopt the proposed directions at the earliest otherwise things may not be favorable for long term perspectives. Strategic HRD directions are considered as the modern competitive edge in today's corporate world. 


\section{Future dimensions of the Case study}

This case study can be a foundation for Business schools \& Corporations to apply the proposed directions in varied departments. Business Faculty, Students, Professionals, HR managers, Marketing managers, IT managers, Finance managers, Trainers and Consultants can apply the proposed directions to evaluate the strength of any company. The proposed directions can be applied separately or a combined basis as mentioned in the comparative analysis of strategic HRD directions.

\section{Conclusion}

This concludes that modern companies have no choice but to adopt the proposed strategic directions in order to achieve the desired organizational productivity. Companies are required to evaluate their position before they decide to adopt the directions. Strategic HRD directions can be adopted by any company any time but will be much better if applied with the basic requirements of Technology, HR managers and a visionary leader at CEO level. This will make sure the effectiveness of utilizing the proposed directions in the company. The study has concluded that the proposed strategic directions are compatible and better than the strategies of past companies. Strategic HRD directions are properly aligned according to the requirement of modern companies. This will lead companies to achieve an organizational productivity. The aspirant CEOs of modern companies need to utilize the proposed strategic HRD directions to lead their companies achieve better productivity. Companies will be in much better position who initiates first and adopt in early times. This is an age of competition and various strategies keep coming but few will prove to be a proper mark for the progress of the company. The study concludes that the proposed directions will be very helpful for modern companies.

\section{References}

Eidems, J. (2011) 'A process perspective on transnational HRM systems - A dynamic capability-based analysis', HRM Review, 21(3), 162-173.

Garavan, TN (1991) SHRD, J of European IndustrialTraining, 15 (1), pp 17-30

Garavan, (2007) A strategic perspective on HRD, advances, Developing HR, pp 11-30

Gold, J, Walton, J, Cureton, P and Anderson, L (2011) Theorising and practitioners in hrd: the role of abductive reasoning, Journal of European Industrial Training, 35 (3)

Grieves, J (2003) Strategic Human Resource Development, Sage, London

Lado, AA and Wilson, MC (1994) Human resource systems and sustained competitive advantage: a competency-based perspective, The Academy of Mgt. Review, 19 (4),

Makadok, R. (2001) 'Toward a synthesis of the resource-based and dynamic-capability views of rent creation', Strategic Management Journal, 22(5), 387-401.

Martin, J. A. (2000) Dynamic Capabilities: what are they?'Strategic Management Journal, 21(10/11), 1105.

Snell, SA (1992) Control theory in strategic human resource management: the mediating effectof administrative information, AOM Journal, 35 (2), pp 292-27

Teece, D. J., Pisano, G. and Shuen, A. (1997) 'DYNAMIC CAPABILITIES AND STRATEGIC MANAGEMENT', Strategic Management Journal, 18(7), 509-533.

Ulrich, D. (1997) Human Resource Champions, Boston: Harvard University Press.

Ulrich, D. and Beatty, D. (2001) 'FROM PARTNERS TO PLAYERS: HRM, 40(4)293 
Winter, S. G. (2002) 'Deliberate Learning and the Evolution of Dynamic Capabilities', Organization Science, 13(3), 339-351.

Acronyms

HRD (Human Resource Development)

HRD (Human Resource Department)

HRM (Human Resources Management)

E-Bus (Electronic Business), E-Com (Electronic Commerce),

E-Logistics (Electronic logistics), E-Phenomena (Electronic Phenomena)

OD (Organizational Development)

T\&D (Training \& Development)

MNCs (Multinational Corporations)

HR Tiers (Human Resource Tiers)

TM Tiers (Technology Management Tiers)

CL Tiers (Corporate Leadership Tiers)

\section{CASE STUDY TEACHING GUIDELINES AND NOTES BRIEF TEACHING NOTES \\ Strategic Dimensionsof Organizational Productivity}

(A Case study on the proposed HRD directions for modern companies)

The basic teaching notes are prepared for the Business Faculty to maintain the discipline and create good learning environment in the class. Business schools must comply with such case based approaches to help students to be more creative in the corporations.

- Overview of the Case Study

Strategic directions towards organizational productivity are dependent on three HRD dimensions, at first, there are HRD Tier that are connecting with leadership in the organization, second is HRD transformation that is the manual workflow towards the technical flow for employees, and third is an e-HRD phenomena (Collaboration) in the modern organizations. This case study is an attempt to propose HRD tiers (TMTechnology Management, HR-Human Resources, CL-Corporate Leadership), HRD Transformation (HR processes \& Developing employees) and HRD collaboration through e-phenomena). This case will report on the strategic directions that are fruitful for organizational productivity. This case study will report on all such parameters that will enhance the productivity as usually planned in the company.

Keywords: Strategic directions, HRD dimensions and Organizational productivity

- Case study purpose $\&$ objectives:

The purpose of the case study is to identify strategic directions through HRD initiatives as Tiers, Transformations \& Collaborations among the departments. The objectives of this case study are to explain the proposed directions to help in achieving organizational productivity. The main purpose \& objective of this case study is to justify the strategic directions \& proposed HRD models that are used by successful MNCs. 


\section{- $\quad$ Research approach \& design:}

A Case study approach is adopted in this research. Since the case is designed to evaluate the directions \& HRD model, a case study approach was considered the best option. This approach can help better to evaluate qualitative \& case based data on some selected MNCs. The case study design is organized in such a way that can identify strategic directions in general and proposed HRD models in particular in order to link the Tiers, Transformation \& Collaboration processes of modern companies.

- The Case study type \& practical impact:

This is a qualitative case study on strategic directions of HRD with special reference to the proposed tiers, transformation \& collaboration aspects of MNCs. The practical impact of this study will be on the business faculty, students, middle managers \& all related to business profession.

\section{- Focused Audience}

The Case is particularly designed for Corporate leaders, Middle managers, Business Faculty \& Students.

\section{- Teaching Approach}

This cases study should be taught in the HRM and Advanced Management classes. The case study must be distributed two days early and assign students to be in different groups. Students should also be assigned an individual strategy as mentioned in the case. One group should also be assigned a comparative analysis an combined overview of the strategic directions. The teacher should have good background of HR \& Management classes. He should select a senior student to be with him as moderator in the class. Students should be guided to browse companies' productivity and their HRD (Human Resource Development) strategies at HR department (Human Resource Department). Students should also be told to check few other strategies from the literature to support the discussion. Teacher may use slides, videos and other discussion material as required. The class must be $U$ shaped with proper temperature and sound system. The teacher must prepare the solutions of the questions given in the case study.

\section{Case Discussion Questions}

a. Case discussion questions (Strategic HRD Tiers)

i. Why HR tier is in the middle of the both other two tiers?

ii. What are the most important strategic tiers if selected any two?

iii. How company should deal with first TM tier in any small company?

iv. What is the role of strategic tiers in the productivity of the company?

v. What CEO should do to make all the tiers most effective than competitors?

b. Case discussion questions (Strategic HRD Transformation)

i. What is HRD social transformation?

ii. Why social transformation of employees can be an effective strategy?

iii. What are the limitations of social transformation in modern companies? 
iv. What companies should do if it is not possible to change their life style through paying them more?

v. What is the role of HR Department in achieving HR Development strategies through social transformation?

c. Case discussion questions (Strategic HRD Collaboration \& Connectivity)

i. What is the role of HR department in organizational collaboration?

ii. Which e-phenomena is more important in modern companies?

iii. Why internal \& external departments should be connected \& collaborated?

iv. What should be the role of employees to maintain the required collaboration?

v. What are the limitations of three proposed e-phenomena?

The End

Failure isn't a crime. Failure to learn from failure is the crime. Walter Wriston

David Olive \& Gita Piramal, The Quotable Tycoon: A treasury of business quotations, Page 82 